\title{
Yaşı Hastaların Ameliyat Sonrası İyileşme Durumlarının Belirlenmesi
}

\section{Determination of Postoperative Recovery Status of Elderly Patients}

\author{
${ }^{1}$ Figen DIĞIN, ${ }^{2}$ Zeynep KIZILCIK ÖZKAN \\ ${ }^{1}$ Kırklareli Üniversitesi Sağlık Bilimleri Fakültesi, Ebelik Bölümü, Kırklareli, Türkiye \\ ${ }^{2}$ Trakya Üniversitesi Sağlık Bilimleri Fakültesi, Hemşirelik Bölümü, Cerrahi Hastalıkları Hemşireliği ABD, Edirne, Türkiye
}

Figen Diğın: https://orcid.org/0000-0003-1861-0221

Zeynep Kızılcık Özkan: https://orcid.org/0000-0003-1892-241X

\begin{abstract}
ÖZ
Amaç: $\mathrm{Bu}$ araştırmanın amacı yaşı hastaların ameliyat sonrası iyileşme durumlarını belirlemektir.

Materyal ve Metot: Tanımlayıcı türde olan bu araştırma, Temmuz 2019-Mart 2020 tarihleri arasında, bir üniversite hastanesinin genel cerrahi ile ortopedi ve travmatoloji kliniklerinde, elektif majör cerrahi uygulanan 167 yaşlı hastanın katılımıyla gerçekleştirildi. Araştırmada veri toplama araçları olarak Hasta Tanıtım Formu ve Ameliyat Sonrası İyileşme İndeksi kullanıldı.

Bulgular: Araştırmaya katılan hastaların yaş ortalamas1 $73,7 \pm 7,5$ y1l, \%58,1'i $(n=97)$ kadın ve $\% 84,4$ 'i $(\mathrm{n}=141)$ ilkokul mezunudur. Hastaların ameliyat sonras iyileşme indeksi puan ortalamaları $2,7 \pm 0,9$ olarak belirlendi. En yüksek puan ortalamasının 3,5 $\pm 1,3$ ile fiziksel aktiviteler ve en düşük puan ortalamasının $2,0 \pm 0,9$ ile genel semptomlar alt boyutunda olduğu belirlendi. Hastaların ameliyat sonrası iyileşme indeksi toplam puan ortalamalarının yaş ile pozitif yönde orta düzey anlamlı ilişki gösterdiği ve cinsiyet, medeni durumu ve geçirilen operasyon tipine göre istatistiksel olarak anlamlı düzeyde farklılık gösterdiği belirlendi $(\mathrm{p}<0,05)$.

Sonuç: Ameliyat sonrası 3. günde yaşlı hastaların ameliyat sonrası iyileşmede çok zorlandığı belirlendi.

Anahtar Kelimeler: Ameliyat sonrası iyileşme indeksi, cerrahi, yaşlı hasta
\end{abstract}

\section{ABSTRACT}

Objective: The aim of this study is to determine the postoperative recovery status of elderly patients.

Materials and Methods: This descriptive study was conducted between July 2019 and March 2020 with the participation of 167 elderly patients who underwent elective major surgery in the general surgery and orthopedics and traumatology clinics of a university hospital. Patient Information Form and Postoperative Recovery Index were used as data collection tools in the study.

Results: The average age of the patients participating in the study was $73.7 \pm 7.5$ year; $58.1 \%(n=97)$ of them were women and $84.4 \%(n=141)$ were primary school graduates. The mean score of the patients' postoperative recovery index was determined as $2.7 \pm 0.9$. It was determined that the highest mean score was $3.5 \pm 1.3$ in physical activities and the lowest mean score was $2.0 \pm 0.9$ in the general symptoms sub-dimension. It was determined that the mean scores of the postoperative recovery index of the patients showed a moderate positive correlation with age and statistically significant differences according to gender, marital status and the type of operation performed $(\mathrm{p}<0.05)$.

Conclusion: On the $3^{\text {rd }}$ postoperative day, it was determined that elderly patients had great difficulty in postoperative recovery.

Keywords: Elderly patient, postoperative recovery index, surgery
Sorumlu Yazar / Corresponding Author:

Figen Diğın

Kırklareli Üniversitesi Sağlık Bilimleri Fakültesi, Ebelik Bölümü,

Kırklareli, Türkiye

Tel: +0 5056461929

E-mail: fgndgn2013@gmail.com
Yayın Bilgisi / Article Info:

Gönderi Tarihi/ Received: 31/03/2021

Kabul Tarihi/ Accepted: 02/06/2021

Online Yayın Tarihi/ Published: 05/09/2021

Atıf / Cited: Dı̆̆ın F ve Kızılcık Özkan Z. Yaşlı Hastaların Ameliyat Sonrası İyileşme Durumlarının Belirlenmesi. Online Türk Sağllk Bilimleri Dergisi 2021;6(3):413-418. doi: 10.26453/otjhs.907564

\section{GíRiş}

Yaşlılar genellikle kardiyovasküler, serebrovasküler, böbrek veya akciğer gibi işlevi azalmış organ hastalıkları nedeniyle sağlık kuruluşlarına başvurmaktadırlar. ${ }^{1}$ Dünya genelinde yaşlı nüfus giderek artmakta ve buna paralel olarak da yaşlı hastalara kademeli olarak artan oranda cerrahi müdahaleler uygulan- maktadır. ${ }^{2}$ Yetmiş yaş ve üstü her beş bireyden birinin 2030 yılına kadar en az bir kez ameliyat olacağı tahmin edilmektedir. ${ }^{3}$ Teknolojik gelişmelerle birlikte yaşlı hastaların fizyolojik yapılarının daha iyi anlaşılması, perioperatif bakım ve anestezi tekniklerinin gelişmesi, yaşlılarda güvenilir cerrahi tedavilerin yapılma oranını arttırmıştır. ${ }^{2}$ Ancak cerrahi, 
anestezi ve yaşl1lık nedeniyle meydana gelen fizyolojik kapasitedeki değişiklikler ameliyat sonrası bireyin biyopsikososyal durumunu olumsuz etkileyebilmektedir. ${ }^{1,4}$

Ameliyat sonrası iyileşme süreci fizyolojik bulgular, psikolojik durum değişiklikleri ve yan etkilerin görülme sıklığı ile ilişkili karmaşık bir durumdur. ${ }^{5} \mathrm{Bu}$ süreç bireyin günlük yaşam aktivitelerinde bağımsızlığa ve biyopsikososyal açıdan optimum düzeye ulaşmayı ve normale dönüşü gerektirir. ${ }^{6}$ Ameliyat sonrası iyileşme kalitesinin en önemli belirleyicilerinin bilişsel işlevsellik, enerji / yorgunluk / uyku, mental sağlık, ağrı, fiziksel işlevsellik, psikososyal işlevsellik, semptomlar vb. olduğu belirtilmektedir. ${ }^{7}$ Ameliyat sonrası iyileşme durumu, hastanın preoperatif değerlendirmesi ve bireysel ihtiyaçlarına göre uyarlanmış bir hemşirelik bakım planının geliştirilmesiyle desteklenmelidir. ${ }^{8}$ Ameliyat sonrası iyileşme döneminde yaşlıların yaşadığı sorunlar belirlenerek, ameliyat öncesi dönemde bu sorunlara yönelik önleyici hazırlıkların yapılması gerekmektedir. ${ }^{9}$

Ameliyat sonrası hastaların iyileşme durumlarının değerlendirilmesinin, ameliyat sonrası yaşam kalitesi için önemli olduğu vurgulanmaktadır. ${ }^{10}$ Literatürde yaşlı hastaların ameliyat sonrası fonksiyonel durumlarının değerlendirmesine yönelik çalışmaların yapılması gerektiği ve ameliyat sonrası iyileşmenin hastanın geri bildirimleri ile değerlendirilmesi gerektiği belirtilmektedir. ${ }^{11}$ Hastaların ameliyat sonrası iyileşme durumlarının değerlendirilmesi için standartlaştırılmış ve geçerli bir ölçme aracı kullanılması önerilmektedir. $^{7}$

$\mathrm{Bu}$ çalışmanın amacı yaşlı hastaların ameliyat sonrası iyileşme durumlarını belirlemektir.

\section{MATERYAL VE METOT}

Araştırmanın Etik Yönü: Araştırma öncesinde Trakya Üniversitesi Tıp Fakültesi Bilimsel Araştırmalar Etik Kurulundan (Tarih:17.06.2019 karar no:11/15) ve çalışmanın yürütüldüğü kurumdan gerekli yazılı izinler alındı. Hastalara araştırma hakkında sözlü bilgi verildi ve araştırmaya katılmaya gönüllü olanlardan yazılı izinleri alındı. Hastalara verdikleri bilgilerin sadece araştırma amacıyla kullanılacağ1 ve gizliliklerinin korunacağı bilgisi verildi. Ameliyat Sonrası İyileşme İndeksi'nin kullanımı için Hande Cengiz'den mail yoluyla izin alındı.

Araştırma Tipi ve Örneklem: Tanımlayıcı türde olan bu araştırma, Temmuz 2019-Mart 2020 tarihleri arasında, bir üniversite hastanesinin genel cerrahi ile ortopedi ve travmatoloji kliniklerinde, elektif majör cerrahi uygulanan 167 yaşlı hastanın katılımıyla gerçekleştirildi.

Araştırmanın evrenini ameliyat olan 65 yaş ve üstü hastalar oluştururken, örnekleme alınması gereken en az kişi sayısı G power programında (3.1.9.4) \%95 güven düzeyinde, etki büyüklüğü 0,3 öngörerek 147 kişi olarak bulundu. Çalışma kapsamında toplam 167 hastaya ulaşıldı. Örnekleme 65 yaş ve üzeri, genel cerrahi (abdominal cerrahi) veya ortopedi ameliyatı uygulanmış, ameliyat sonrası genel cerrahi/ortopedi ve travmatoloji servisinde takip edilen, çalışmaya katılmaya gönüllü olan, mental problemi olmayan, psikiyatrik hastalık tanısı koyulmamış, psikiyatrik ilaç kullanmayan hastalar dahil edildi. Araştırmaya postoperatif deliryumu olan hastalar dahil edilmedi.

Veri Toplama Araçları: Araştırmada veri toplama araçları olarak Hasta Tanıtım Formu ve Ameliyat Sonrası İyileşme İndeksi kullanıldı.

Hasta Tanıtım Formu: Araştırmacılar tarafindan literatür desteği ${ }^{1,12}$ ile hazırlanan formda sosyodemografik özellikleri (yaş, cinsiyet, eğitim durumu, medeni durum, sigara tüketimi, alkol kullanımı, komorbidite, boy, kilo, beden kitle indeksi ve cerrahi deneyimi) ve hastalıkla ilişkili özellikleri (uygulanan cerrahi işlem) sorgulayan toplam on iki adet soru bulunmaktadir.

Ameliyat Sonrası İyileşme Indeksi (ASİi): Ameliyat Sonrası İyileşme İndeksi; 2012 yılında Butler ve arkadaşları tarafından geliştirilmiş ve Cengiz ve Aygin (2019) tarafından Türkçe geçerlilik ve güve-

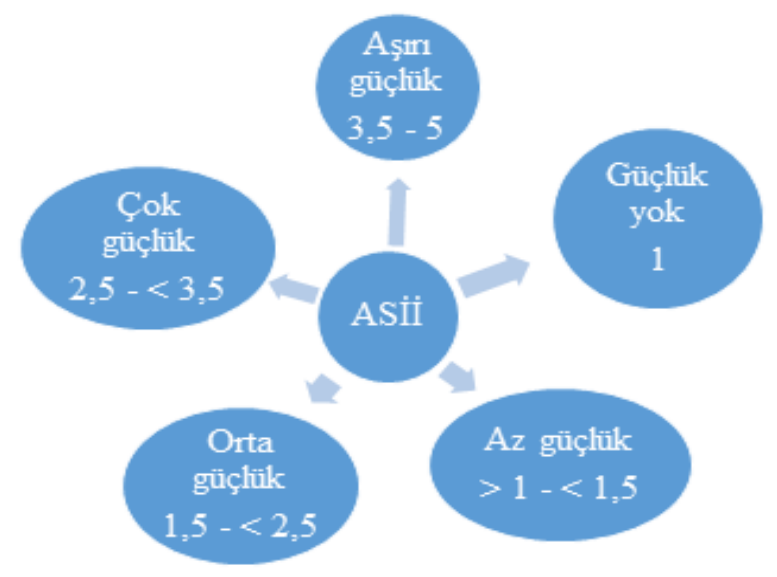

Şekil 1. ASİ̇ toplam ve alt boyut puan değerlendirmeleri $^{12}$

nilirlik çalışması yapılmıştır. İndex 5 alt boyut ve 25 maddeden oluşmaktadır. Alt boyutlar; psikolojik semptomlar, fiziksel aktiviteler, genel semptomlar, 
bağırsak semptomları ve istek-arzu semptomlarıdır. Alt boyut puanı belirlenirken, ilgili maddelerin puanları toplanmakta ve aritmetik ortalamaları alınmaktadır. Toplam puan için; tüm maddeler toplanarak aritmetik ortalaması alınmaktadır. İndeksten alınan yüksek puanlar ameliyat sonrası iyileşmede daha fazla güçlük yaşandığını yansıtırken, alınan düşük puanlar ameliyat sonrası iyileşmenin daha kolay olduğunu belirtmektedir (Şekil 1). ${ }^{12}$ Cengiz ve Aygin'in çalışmasında ASIII' 'nin Cronbach alfa değeri 0,96 olarak belirlenmiştir. ${ }^{12} \mathrm{Bu}$ çalışmada Cronbach alfa değeri 0,95 olarak bulundu.

Verilerin Toplanması: Araştırmanın verileri Hasta tanıtım formu ve ASIII kullanılarak topland. Veri toplama formları hasta odasında, postoperatif 3. gün- de ve hastalar ile yüz yüze görüşülerek uygulandı.

Verilerin Değerlendirilmesi: Veriler ortalama, standart sapma, frekans ve yüzde gibi tanımlayıcı istatistikler ile ifade edildi. Verilerin analizinde IBM SPSS 22.0 kullanıld1. Veriler Mann-Whitney U testi, Kruskal Wallis $H$ testi ve Spearman korelasyon testleri ile analiz edildi. İstatistik analizlerde anlamlılık değeri $\mathrm{p}<0,05$ olarak belirlendi.

\section{BULGULAR}

Hastaların ortalama yaşının $73,7 \pm 7,5$ yıl ve \% 58,1'inin (n=97) kadın olduğu ve \%84,4'ünün ilköğretim mezunu olduğu belirlendi. Hastaların \% 72,5'ine ortopedik cerrahi girişim uygulandı (Tablo $1)$.

Tablo 1. Hastaların sosyodemografik değişkenlere göre ameliyat sonrası iyileşme indeksi toplam puan or talamalarının karşılaştırılması ( $\mathrm{n}=167)$.

\begin{tabular}{|c|c|c|c|c|c|}
\hline \multicolumn{2}{|l|}{ Değişskenler } & $\mathbf{n}$ & $\%$ & $\begin{array}{c}\text { ASİI } \\
\text { Sira ortalaması } \\
\end{array}$ & İstatistiksel değerler \\
\hline \multicolumn{2}{|l|}{ Yaşy $_{\mathrm{yl}}(\operatorname{Ort} \pm \mathrm{SS})$} & \multicolumn{2}{|c|}{$73,7 \pm 7,5$} & & $\begin{array}{l}\mathbf{p}=\mathbf{0 , 0 0 0} \\
r=0,423\end{array}$ \\
\hline \multirow[b]{2}{*}{ Cinsiyet } & Kadın & 97 & 58,1 & 93,71 & \multirow{2}{*}{$\begin{array}{c}\mathbf{p}=\mathbf{0 , 0 0 2} \\
\mathrm{U}=2453,500\end{array}$} \\
\hline & Erkek & 70 & 41,9 & 70,55 & \\
\hline \multirow[b]{3}{*}{ Eğitim durumu } & İlköğretim & 141 & 84,4 & 85,17 & \multirow{3}{*}{$\begin{array}{c}\mathrm{p}=0,756 \\
\mathrm{KW}=0,558\end{array}$} \\
\hline & Ortaöğretim & 13 & 7,8 & 76,15 & \\
\hline & Yükseköğretim & 13 & 7,8 & 79,12 & \\
\hline \multirow{2}{*}{ Medeni durum } & Evli & 132 & 79,0 & 76,34 & \multirow{2}{*}{$\begin{array}{c}\mathbf{p}=\mathbf{0 , 0 0 0} \\
U=1299,000\end{array}$} \\
\hline & Bekar & 35 & 21,0 & 112,89 & \\
\hline \multirow[b]{2}{*}{ Sigara tüketimi } & Evet & 10 & 6,0 & 60,70 & \multirow{2}{*}{$\begin{array}{c}\mathrm{p}=0,116 \\
\mathrm{U}=552,000\end{array}$} \\
\hline & Hayır & 157 & 94,0 & 85,48 & \\
\hline \multirow{2}{*}{ Alkol kullanımı } & Evet & 3 & 1,8 & 43,50 & $\mathrm{p}=0,143$ \\
\hline & Hayır & 164 & 98,2 & 84,74 & $\mathrm{U}=124,500$ \\
\hline \multirow{2}{*}{ Komorbidite } & Evet & 123 & 73,7 & 82,08 & $\mathrm{p}=0,391$ \\
\hline & Hayır & 44 & 26,3 & 89,36 & $\mathrm{U}=2470,000$ \\
\hline \multirow{2}{*}{ Cerrahi deneyimi } & Evet & 92 & 55,1 & 69,60 & $\mathbf{p}=\mathbf{0 , 0 0 0}$ \\
\hline & Hayır & 75 & 44,9 & 101,66 & $\mathrm{U}=2125,500$ \\
\hline \multirow{2}{*}{$\begin{array}{l}\text { Uygulanan cerrahi } \\
\text { işlem }\end{array}$} & Genel cerrahi & 46 & 27,5 & 38,92 & $\mathbf{p}=\mathbf{0 , 0 0 0}$ \\
\hline & Ortopedik cerrahi & 121 & 72,5 & 101,14 & $\mathrm{U}=709,500$ \\
\hline \multicolumn{2}{|c|}{ Beden kitle indeksi $\mathrm{kg}_{\mathrm{kg}}{ }^{2}($ Ort $\pm \mathrm{SS})$} & \multicolumn{2}{|c|}{$27,8 \pm 5,5$} & & $\begin{array}{l}\mathrm{p}=0,339 \\
\mathrm{r}=-0,074\end{array}$ \\
\hline
\end{tabular}

Hastaların ASİİ toplam puan ortalamalarının yaş ile pozitif yönde orta düzeyde anlamlı ilişki gösterdiği ve cinsiyet, medeni durum, cerrahi deneyim ve uygulanan cerrahi işleme göre istatistiksel olarak anlamlı düzeyde farklılık gösterdiği belirlendi (Tablo
1).

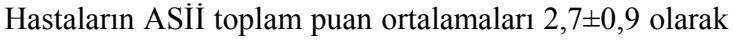

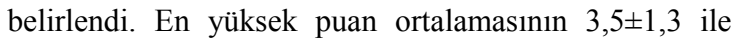
fiziksel aktiviteler ve en düşük puan ortalamasının $2,0 \pm 0,9$ ile genel semptomlar alt boyutunda olduğu belirlendi (Tablo 2). 
Tablo 2. Hastaların ameliyat sonrası iyileşme indeksi toplam ve alt boyut puan ortalamaları $(\mathrm{n}=167)$.

\begin{tabular}{|l|c|c|}
\hline Ölçek ve alt boyutları & Ort \pm SS & Min- \\
\hline Psikolojik semptomlar & $2,1 \pm 1,1$ & $1-5$ \\
\hline Fiziksel aktiviteler & $3,5 \pm 1,3$ & $1-5$ \\
\hline Genel semptomlar & $2,0 \pm 0,9$ & $1-5$ \\
\hline Bağırsak semptomları & $2,1 \pm 0,9$ & $1-5$ \\
\hline İstek-arzu & $3,2 \pm 1,4$ & $1-5$ \\
\hline Toplam ASi̇ & $2,7 \pm 0,9$ & $1,0-4,6$ \\
\hline
\end{tabular}

\section{TARTIŞMA VE SONUÇ}

Araştırmada hastaların yaşı ilerledikçe ameliyat sonrası iyileşmelerinin daha güçleştiği belirlendi. Benzer şekilde bir çalışmada yaşın ameliyat sonrası iyileşmeyi olumsuz etkilediği belirlenmiştir. ${ }^{12}$ Kim ve ark. ${ }^{2}$ gastrektomi uygulanan yaşlı hastalarda yaşın postoperatif komplikasyonlar üzerinde yordayıcı bir faktör olduğunu bildirmişlerdir. Lin ve ark. ${ }^{13}$ lomber skolyoz cerrahisi uygulanan 70 yaş üstü hastaların ameliyat sonrası iyileşme açısından risk altında olduğunu belirlemişlerdir. Daha önce bildirildiği gibi yaşlanma ile birlikte komorbidite, kırılganlık, psikolojik ve sosyal bakım sorunlarının ortaya çıkma ${ }^{14}$ riski yüksektir ve bu durumun etkisiyle postoperatif iyileşmenin güçleştiği açıklanabilir.

Kadın hastaların erkek hastalara göre ameliyat sonrası iyileşmede daha fazla güçlük yaşadığı belirlenirken, Cengiz ve ark. ${ }^{12}$ çalışmalarında da ameliyat sonrası kadınların iyileşme konusunda daha fazla güçlük yaşadığı bildirilmiştir. Rahman ve ark. ${ }^{15}$ erkeklerin postoperatif iyileşme kalitesinin kadınlara göre daha iyi düzeyde olduğunu belirlemişlerdir. Yolcu ve Akın'ın çalışmasında ${ }^{16}$ kadın hastaların mobilizasyon konusunda erkek hastalara göre desteklenme ihtiyacının daha fazla olduğu belirlenmiştir. Cinsiyetin postoperatif iyileşme üzerinde etkisini değerlendiren bir çalışmada kadın olmanın ameliyat sonrası daha zayıf iyileşme kalitesiyle ilişkilendirildiği görülmüştür. ${ }^{17}$ Çalışma sonuçları baz alınarak, kadın hastalarda postoperatif iyileşmenin erkek hastalara göre daha güç olduğu söylenebilir.

Bekar hastaların evli hastalara göre ameliyat sonrası iyileşmede daha fazla güçlük yaşadığı belirlenirken, Ali ve ark. ${ }^{18}$ maksillektomi sonrası evli hastalarda yaşam kalitesinin daha iyi düzeyde olduğunu bildirmişlerdir. Elektif omurga cerrahisi uygulanan ${ }^{19}$ ve pankreatoduodenektomi uygulanan ${ }^{20}$ bekar hastalarda evlilere göre hastanede yatış süresinin daha uzun olduğu bulunmuştur. Diğer bir çalışmada $^{21}$ total kalça artroplastisi uygulanan hastalarda cerrahi sonrası fonksiyonel sonuçların bekar hastalarda daha kötü olduğu belirlenmiştir. O’Neill ve ark. ${ }^{22}$ kalitatif çalışmasına katılan gastrointestinal kanser tanılı hastalara göre psikososyal destek, ameliyat sonrası iyileşme üzerinde olumlu bir etkendir. Bu bilgiler doğrultusunda hastaların eş varlığında sosyal ve duygusal ihtiyaçlarının daha fazla karşılanmış olabileceği öngörülerek postoperatif iyileşmenin evli hastaların lehine daha kolay olduğu düşünülmektedir.

Ortopedik cerrahi uygulanan hastaların genel cerrahi kliniğindeki hastalara göre iyileşmelerinin daha zor olduğu belirlenirken, benzer şekilde Berg ve ark. ${ }^{23}$ çalışmalarında ortopedik hastaların, genel cerrahi hastalarına göre 14. günde daha düşük postoperatif iyileşme gösterdiği bildirilmiştir. Rahman ve ark. ${ }^{15}$ ortopedi hastalarında postoperatif iyileşme kalitesinin genel cerrahi hastalarına göre daha zor olduğunu belirlemişlerdir. Başka bir çalışmada fiziksel olarak daha az aktif olan hastalarda ameliyat sonrası komplikasyon görülme oranının ve hastaneye yeniden yatışların daha fazla olduğu bulunmuştur. ${ }^{24}$ Sonuç olarak ortopedi hastalarının diğer cerrahi hastalarına göre fiziksel aktivitelerini daha kısıtlı olması nedeniyle iyileşmelerinin daha zaman alıcı olduğu ve iyileşmelerinin daha güç olduğu söylenebilir.

Araştırmada hastaların ameliyat sonrası iyileşmede çok güçlük yaşadığı belirlendi. Kalitatif bir çalışmada, ${ }^{25}$ kolorektal kanser cerrahi uygulanan hastalarda postoperatif ilk zamanlarda fiziksel zorlanma ve bağırsak fonksiyonlarında anormallik gibi problemlerin daha yoğun yaşandığ 1 ancak zamanla bu sıkıntıların azaldığ 1 ve ortadan kalktığ 1 bildirilmiştir. Yine aynı çalışmada erken postoperatif iyileşme döneminde hastaların profesyonel desteğe daha fazla ihtiyaç duyduğu belirlenmiştir. Dahlberg ve ark. ${ }^{26}$ günübirlik cerrahi hastalarının katılımıyla gerçekleştirdiği çalışmalarında hastaların \%62'sinin taburculuk sonrası özellikle cerrahi yara ve insizyonel ağrı nedeniyle ameliyat sonrası derlenmeye yönelik sorunlar yaşadığını ve sağlık profesyonellerine ulaşma çabasında olduklarını belirlemişlerdir. Dolayısıyla örneklem grubumuzda hem yaşlanmanın doğası ile hem de cerrahinin etkisiyle postoperatif erken dönemde zorlanma yaşanması kabul edilebilir bir sonuçtur.

Hastaların özellikle fiziksel aktiviteler (günlük aktivitelerini yapabilme, kendi kendine banyo yapabilme vb.) alt boyutunda aşırı güçlük yaşadığı belirlenirken, Deschler ve ark. $^{27}$ onkolojik cerrahi uygulanan yaşlı hastalarda taburculuk sırasında ameliyat öncesine göre fonksiyonel kapasitede azalma ve semptom yükünde artış olduğunu belirlemişlerdir. O'Neill ve ark. ${ }^{22}$ çalışmalarında gastrointestinal onkolojik cerrahi uygulanan hastaların postoperatif iyileşmeyi olumsuz etkileyen fiziksel ve psikososyolojk problemler yaşadığını bildirmişlerdir. Ortopedi hastalarının örneklemi oluşturduğu çalışmalarda ${ }^{28,29}$ hastalarda postoperatif iyileşme göstergesi olarak kabul edilen eklem fonksiyonelliği, ağrı, sertlik gibi fiziksel sorunların yaşandığı ve hastaların günlük yaşam aktivitelerinde bir yakınının desteğine ihtiyacı olduğunu bildirmişlerdir. AmarillaDonoso ve ark. ${ }^{30}$ kalça fraktürü nedeniyle cerrahi uygulanan yaşlılarda postoperatif 1 . ayda hastaların yaşam kalitelerinin ameliyat öncesine göre ciddi düşük seyrettiğini bildirmişlerdir. Çalışma sonuçları, cerrahi sonrası hastaların fiziksel aktivitelerini gerçekleştirmede zorlandıklarını ve kısmen desteğe ihtiyaç duyduklarını ortaya koymaktadir.

Sonuç olarak, ameliyat sonrası 3. günde yaşlı hastaların 
ameliyat sonrası iyileşmede çok zorlandığı bulundu. Genel cerrahi ya da ortopedi ve travmatoloji kliniklerinde çalışan cerrahi hemşirelerinin yaşlı hastaları ameliyat sonrası iyileşmeleri konusunda desteklemeleri önerilir. Özellikle ameliyat sonrası iyileşme açısından risk grubunda yer alan ileri yaştaki, kadın, bekar ve/veya ortopedik cerrahi uygulanan hastaları ameliyat sonrası dönemde derlenmeyi güçlendirmek ve hızlandırmak açısından gözlemlemeleri ve destek gereken durumlarda yardımcı olmaları önerilir. $\mathrm{Bu}$ çalışmanın bazı sınırlılıkları mevcuttur. Öncelikle hastaların ameliyat sonrası iyileşmelerini etkileyebilecek öz bakım gücü ve sosyal destek varlığı gibi faktörler sorgulanmamıştır. Ek olarak araştırma bulguları örneklemle sınırlıdır, genellenemez. Ancak bu araştırma ortopedik veya genel cerrahi uygulanan yaşlı hastalarda ameliyat sonrası iyileşme durumunu geçerli ve standardize bir ölçek ile sorgulayan ulusal ölçekte öncü bir çalışmadır.

Etik Komite Onayı: Araştırma öncesinde Trakya Üniversitesi Tıp Fakültesi Bilimsel Araştırmalar Etik Kurulundan (Tarih:17.06.2019 karar no:11/15) ve çalışmanın yürütüldüğü kurumdan gerekli yazılı izinler alındı.

Çıkar Çatışması: Yazarlar çıkar çatışması beyan etmemektedir.

Yazar Katkllart: Fikir FD; Denetleme; FD, ZKÖ; Veri toplanması ve/veya işlenmesi: FD, ZKÖ; Analiz ve yorum: FD, ZKÖ; Yazıy1 yazan: FD, ZKÖ.

Hakem Değerlendirmesi: Dış bağımsız.

\section{KAYNAKLAR}

1. Lirosi MC, Tirelli F, Biondi A, ve ark. Enhanced recovery program for colorectal surgery: a focus on elderly patients over 75 years old. J Gastrointest Surg. 2019;23:587-594.

2. Kim SM, Youn HG, An JY, ve ark. Comparison of open and laparoscopic gastrectomy in elderly patients. J Gastrointest Surg. 2018;22(5):785-791.

3. Fowler AJ, Abbotto TEF, Prowle J, Pearse RM. Age of patients undergoing surgery. Br J Surg. 2019;106 (8):1012-1018.

4. Aygin D. Yaşlı cerrahisinde bakım. İç: Cerrahi bakım vaka analizleri ile birlikte (Ed FE Aslan). Ankara: Akademisyen Tip Kitabevi; 2017:181-247.

5. Lee L, Tran T, Mayo NE, Carli F, Feldman LS. What does it really mean to "recover" from an operation? Surgery. 2014;155(2):211-216.

6. Berg K, Idwall E, Nilsson U, Arestedt KF, Unosson M. Psychometric evaluation of the post-discharge surgical recovery scale. J Eval Clin Pract, 2010;16 (4):794-801.

7. Wu CL, Richman JM. Postoperative pain and quality of recovery. Curr Opin Anaesthesiol. 2004;17(5):455 -460 .

8. Gustafsson S, Strömqvist M, Ekelund J, Engström Å. Factors influencing early postoperative recovery after laparoscopic cholecystectomy. J PeriAnesth
Nurs. 2020;35:80-84.

9. Yılmaz M. Cerrahi hastanın değerlendirilmesi. İç: Cerrahi bakım vaka analizleri ile birlikte (Ed FE Aslan). Ankara: Akademisyen Tip Kitabevi; 2017;281-317.

10. Herrera FJ, Wong J, Chung F. A systematic review of postoperative recovery outcomes measurements after ambulatory surgery. Anesth Analg. 2007;105 (1):63-69.

11. Brinson Z, Tang VL, Finlayson E. Postoperative functional outcomes in older adults. Curr Surg Rep. 2016;4(6):21.

12. Cengiz H, Aygin D. Validity and reliability study of the Turkish version of the Postoperative Recovery Index of patients undergoing surgical intervention. Turk J Med Sci. 2019;49:566-573.

13. Lin T, Meng Y, Li T, Jiang H, Gao R, Zhou X. Predictors of postoperative recovery based on healthrelated quality of life in patients after degenerative lumbar scoliosis surgery. World Neurosurg. 2018;109:539-545.

14. Chong RC, Ong MW, Tan KY. Managing elderly with colorectal cancer. J Gastrointest Oncol. 2019;10 (6):1266-1273.

15. Rahman ARA, Mahdy NE, Kamaly A. Predictive factors affecting postoperative quality of recovery for patients undergoing surgery. IOSR-JNHS. 2017;6 (3):50-60.

16. Yolcu S, Akın S. Ortopedi, kalp ve genel cerrahi ameliyatları sonrası dönemde hastaların iyileşme durumları ve bakım gereksinimlerinin değerlendirilmesi. Sağlık ve Toplum. 2015;25(3):33-45.

17. Buchanan FF, Myles PS, Cicuttini F. Effect of patient sex on general anaesthesia and recovery. Br J Anaesth. 2011;106(6):832-839.

18. Ali MM, Khalifa N, Alhajj N. Quality of life and problems associated with obturators of patients with maxillectomies. Head \& Face Medicine. 2018;14 (2):1-9.

19. Adogwa O, Elsamadicy AA, Vuong VD, ve ark. Effect- of social support and marital): status on perceived surgical effectiveness and 30-day hospital readmission. Global Spine J. 2017;7(8)774-779.

20. Flick K, Sublette CM, Yip-Schneider MT, ve ark. Insurance type and marital status impact hospital length of stay after pancreatoduodenectomy. J Surg Res. 2021;257:587-592.

21. Lall AC, Schwarzman GR, Battaglia MR, Chen SL, Maldonado DR, Domb BG. Effect of marital status on patient-reported outcomes following total hip arthroplasty: a matched analysis with minimum 2year follow-up. HIP International. 2019; 31328566.

22. O’Neill L, Bennett A, Guinan E, Reynolds JV, Hussey J. Physical recovery in the first six months following oesophago-gastric cancer surgery. Identifying rehabilitative needs: a qualitative interview study. 
Disabil Rehabil. 2019;31524528. doi: 10.1080/09638288.2019.1663946

23. Berg K, Kjellgren K, Unosson M, Arestedt K. Postoperative recovery and its association with healthrelated quality of life among day surgery patients. BMC Nurs. 2012;11:24

24. Jonker LT, Lahr MM, Oonk MHM, de Bock GH, van Leeuwen BL. Post-discharge telemonitoring of physical activity, vital signs, and patient-reported symptoms in older patients undergoing cancer surgery. Ann Surg Oncol. 2021;33641013. doi:10.1245/ s10434-021-09707-3

25. Jakobsson J, Idwell E, Kumlien C. The lived experience of recovery during the first 6 months after colorectal cancer surgery. J Clin Nurs. 2017;7 (26):4498-4505.

26. Dahlberg K, Jaensson M, Nilsson U. "Let the patient decide" - Person-centered postoperative follow-up contacts, initiated via a phone app after day surgery: Secondary analysis of a randomized controlled trial. IJS. 2019;61:33-37.

27. Deschler B, Ihorst G, Hüll M, Baier P. Regeneration of older patients after oncologic surgery. A temporal trajectory of geriatric assessment and quality of life parameters. J Geriatr Oncol. 2019;10:112-119.

28. Sjoveian AKH, Leegaard M. Hip and knee arthroplasty - patient's experiences of pain and rehabilitation after discharge from hospital. Int J Orthop Trauma Nurs. 2017;27:28-35. doi:10.1016/ j.ijotn.2017.07.001

29. Sabharwal S, Archer S, Cadoux-Hudson D, Griffiths D, Gupte CM, Reilly P. Exploring elderly patients' experiences of recovery following complex proximal humerus fracture: A qualitative study. J Health Psychol. 2021;26(6):880-891. doi:10.1177/1359105319850883

30. Amarilla-Donoso FJ, López-Espuela F, RonceroMartín R, ve ark. Quality of life in elderly people after a hip fracture: a prospective study. Health Qual Life Outcomes. 2020;18(1):71. doi:10.1186/s12955020-01314-2 